\title{
Malignant transformation of a gastric hyperplastic polyp in a context of Helicobacter pylori-negative autoimmune gastritis: a case report
}

Kenichi Yamanaka ${ }^{1 *}$, Hiroyuki Miyatani ${ }^{1}$, Yukio Yoshida ${ }^{1}$, Takehiro Ishii ${ }^{1}$, Shinichi Asabe ${ }^{1}$, Osamu Takada ${ }^{2}$, Mitsuhiro Nokubi ${ }^{3}$ and Hirosato Mashima ${ }^{1}$

\begin{abstract}
Background: Gastric foveolar hyperplastic polyps (GFHPs) are common findings in clinical practice. GFHPs commonly arise in a background of chronic atrophic gastritis, including autoimmune gastritis (type A gastritis), and have a potential risk of malignant transformation.

Case presentation: In 2005, a 55-year-old Japanese woman underwent upper endoscopy at another hospital and was found to have a pedunculated polyp (10 $\mathrm{mm}$ in diameter) on the greater curvature of the lower gastric body. On biopsy, the polyp was diagnosed as a GFHP. Nine years later, the polyp had grown to $20 \mathrm{~mm}$ in diameter, and the biopsy specimen taken at this time showed tubular adenocarcinoma. On admission to our hospital, the serum Helicobacter Pylori (H. pylori) immunoglobulin G antibody and stool H. pylori antigen were both negative. Anti-gastric parietal cell antibody was positive, as was the anti-intrinsic factor antibody, and the fasting serum gastrin level was markedly increased. In 2014, en bloc resection of the pedunculated polyp was performed by endoscopic submucosal dissection. The final histological diagnosis was adenocarcinoma of the stomach with submucosal and lymphatic invasion. Subsequently, additional radical distal gastrectomy was performed. At the latest follow-up (12 months postoperatively), no recurrence was noted.

Conclusions: We here reported a rare case of malignant transformation of GFHP arising in a context of type A gastritis. To our knowledge, there are no previous reports on malignant transformation of GFHP with submucosal and lymphatic invasion arising in a background of type A gastritis in the English literature. Further, there is currently no effective treatment other than endoscopic or surgical treatment for such cases. Given the potential risk of malignant transformation due to hypergastrinemia, we consider that endoscopic treatment should be considered as a first-line therapy when a malignant growth is suspected.
\end{abstract}

Keywords: Gastric hyperplastic foveolar polyp, Autoimmune gastritis, Helicobacter pylori, Gastric carcinoma, Case report

\footnotetext{
* Correspondence: yken211@omiya.jichi.ac.jp

'Department of Gastroenterology, Jichi Medical University, Saitama Medical

Center, Saitama 330-8503, Japan

Full list of author information is available at the end of the article
} 


\section{Background}

Gastric foveolar hyperplastic polyps (GFHPs) are common findings in clinical practice. They do not regress or disappear spontaneously and are associated with a risk of malignant transformation in $0.6-4.5 \%$ of cases [1-5]. GFHPs commonly arise in a background of chronic atrophic gastritis, including both type B gastritis, associated with Helicobacter Pylori (H. pylori) infection, as well as type A gastritis (autoimmune gastritis) [6]. In Japan, type B gastritis accounts for $>76 \%$ of all gastritis cases $[7,8]$. A previous study reported that eradication of $H$. pylori led to regression and disappearance of gastric hyperplastic polyps in approximately $70 \%$ of patients [9]. In this context, $H$. pylori eradication therapy is recommended in Japan. However, H. pylori eradication therapy is not effective for all cases, particular for GFHPs arising in a background of autoimmune gastritis (type A gastritis). With the increased prevalence and effectiveness of $H$. pylori eradication therapy, the clinical impact of autoimmune gastritis, and thereby also of GFHPs, is rising. There is currently no effective treatment other than endoscopic or surgical treatment for GFHPs arising in a background of $H$. pylori-negative type A gastritis. Therefore, endoscopic treatment is recommended as the firstline therapy when a malignant growth is suspected.

\section{Case presentation}

In November 2005, a 55-year-old Japanese woman underwent upper endoscopy at another hospital and was found to have a pedunculated polyp, measuring $10 \mathrm{~mm}$ in diameter, on the greater curvature of the lower gastric body (Fig. 1a). On biopsy, it was diagnosed as a GFHP. At the moment of the first diagnosis, there was only an endoscopic report and the endoscopic appearance could be compatible with an atrophic mucosa. In January 2013, upper endoscopy was repeated, which revealed that the polyp had grown to $12 \mathrm{~mm}$ in diameter with a slightly rounded head (Fig. 1b). Biopsy was not performed at the time.

In June 2014, the patient underwent positron emission tomography-computed tomography to evaluate the treatment effect on her right breast cancer, for which she had undergone surgery and received chemotherapy and radiation therapy at the age of 53 years. There was an abnormal accumulation in the lower gastric body (Fig. 2). Subsequent upper endoscopy showed that the polyp had grown to $20 \mathrm{~mm}$ in diameter, and the surface of the head was slightly reddish and tense (Fig. 1c). The biopsy specimen obtained from the head of the polyp was histologically diagnosed as tubular adenocarcinoma and was determined to be unrelated to the breast cancer. It was suggested that the polyp became malignant during the nine years of follow-up, and the patient was referred to our institution for further evaluation and treatment.

\section{Physical examination}

On physical examination, scars from the right breast mastectomy with bilateral axillary lymph node dissection were noted. No other remarkable findings were observed.

\section{Laboratory data (Table 1)}

No abnormalities were found in the blood counts or liver and renal function tests. The serum $H$. pylori immunoglobulin G antibody and stool $H$. pylori antigen were both negative. The anti-gastric parietal cell antibody was positive (80-fold increase), as was the anti-intrinsic factor antibody. The fasting serum gastrin level was markedly increased at $>3000 \mathrm{pg} / \mathrm{ml}$ (normal range, $<200 \mathrm{pg} / \mathrm{ml}$ ). The serum pepsinogenI level and pepsinogen I/II ratio were both low (Table 1).
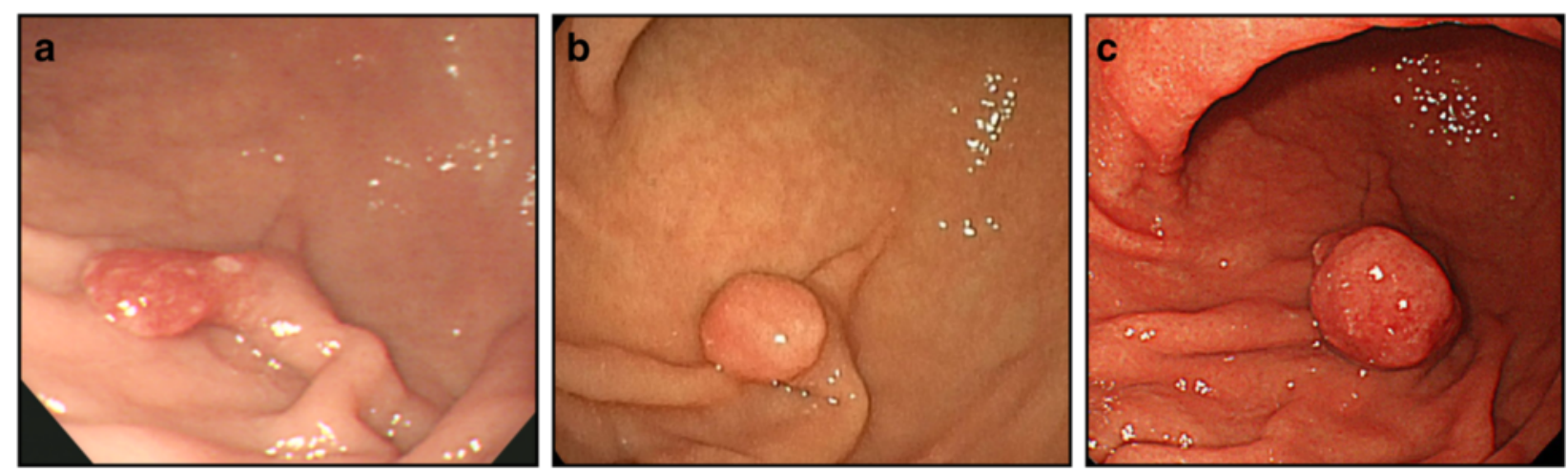

Fig. 1 Endoscopy findings. a. In 2005, a pedunculated polyp measuring approximately 10 mm in diameter was observed on the greater curvature of the lower gastric body. The surface of the polyp was slightly reddish. On biopsy, the lesion was diagnosed as a hyperplastic foveolar polyp. b. In 2013, the pedunculated polyp on the greater curvature of the lower gastric body had grown to $12 \mathrm{~mm}$ in diameter. The head of the polyp was more rounded compared to the image taken in 2005. c. In 2014, the pedunculated polyp on the greater curvature of the lower gastric body had grown to $20 \mathrm{~mm}$ in diameter. The head of the polyp was slightly reddish, more rounded, and tense 


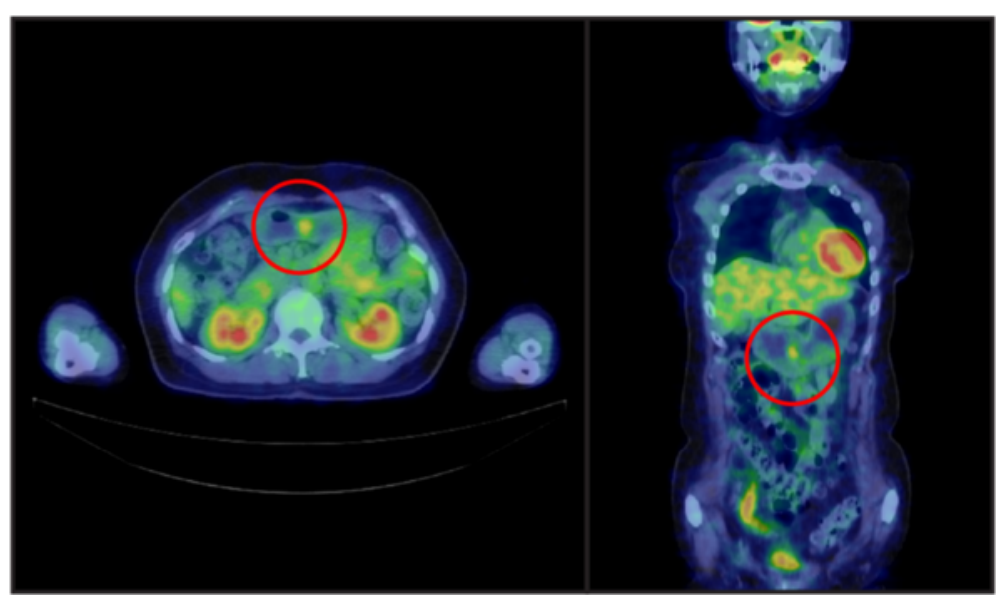

Fig. 2 Positron emission tomography-computed tomography findings. A well-circumscribed mass was observed in the lower gastric body, with a maximum standardized uptake value of 2.7

\section{Medication}

The patient was not taking any medication at the time.

\section{Positron emission tomography-computed tomography (July 2014) (Fig. 2)}

A well-circumscribed mass with a maximum standardized uptake value of 2.7 was observed in the lower gastric body. There were no findings suggesting the presence of gastrinoma.

\section{Clinical course}

In August 2014, en bloc resection of the pedunculated polyp, measuring $20 \mathrm{~mm}$ in diameter, on the greater curvature of the lower gastric body was performed by endoscopic submucosal dissection (Fig. 3).
Histopathological examination showed tumor lesions, which had well-defined borders with hyperplastic glands (Fig. 4a, b). The tumor lesions were strongly positive for p53 and Ki-67, while the hyperplastic lesions were not (Fig. 4c). Submucosal invasion was observed in the stalk, with an invasion depth of $300 \mu \mathrm{m}$ (Fig. 4d). In D2-40positive and cluster of differentiation 34-negative lymph ducts, cells with acidophilic cytoplasm and large nuclei were observed. The cells were positive for keratin, indicating lymphovascular invasion (Fig. 4e). As a result the final histological diagnosis was adenocarcinoma of the stomach, tubular adenocarcinoma > papillary adenocarcinoma, size of resected lesion $20 \mathrm{~mm}$ in size, submucosal invasion of $0.3 \mathrm{~mm}$, venous invasion (-), lymphatic invasion $(+)$.

Table 1 Laboratory data

\begin{tabular}{|c|c|c|c|c|c|}
\hline Hematological analysis & Value & Unit & Blood chemistry & Value & Unit \\
\hline White blood cell count & 4800 & $/ \mu l$ & $\mathrm{TP}$ & 7.3 & g/dl \\
\hline Hemoglobin & 11.9 & $\mathrm{~g} / \mathrm{dl}$ & Alb & 4.4 & $\mathrm{~g} / \mathrm{dl}$ \\
\hline Hematocrit & 37.8 & $\%$ & T-bil & 0.81 & $\mathrm{mg} / \mathrm{dl}$ \\
\hline \multirow[t]{2}{*}{ Platelets } & $19.5 \times 10^{4}$ & $/ \mu l$ & D-bil & 0.24 & $\mathrm{mg} / \mathrm{dl}$ \\
\hline & & & AST & 34 & $U / L$ \\
\hline Tumor markers & & & ALT & 25 & $U / L$ \\
\hline Carcinoembryonic antigen & 1.3 & $\mathrm{ng} / \mathrm{ml}$ & $\mathrm{LDH}$ & 197 & $U / L$ \\
\hline \multirow[t]{2}{*}{ Cancer antigen-15-3 } & 17.1 & $\mathrm{U} / \mathrm{ml}$ & Y-GTP & 16 & IU/I \\
\hline & & & BUN & 11 & $\mathrm{mg} / \mathrm{dl}$ \\
\hline Anti-parietal cell antibody & 80 & fold & Cre & 0.55 & $\mathrm{mg} / \mathrm{dl}$ \\
\hline Anti-intrinsic factor antibody & + & & Gastrin & $>3000$ & $\mathrm{pg} / \mathrm{dl}$ \\
\hline Pepsinogen I & 7.6 & $\mathrm{ng} / \mathrm{ml}$ & Vit B12 & 208 & $\mathrm{pg} / \mathrm{ml}$ \\
\hline Pepsinogen II & 16.3 & $\mathrm{ng} / \mathrm{ml}$ & & & \\
\hline Pepsinogen I/II/ ratio & $<0.5$ & $\mathrm{ng} / \mathrm{ml}$ & & & \\
\hline
\end{tabular}

Abbreviations: TP total protein, $A l b$ albumin, $T$-bil total bilirubin, $d$-bil direct bilirubin, $A S T$ aspartate aminotransferase, $A L T$ alanine aminotransferase, $L D H$ lactate dehydrogenase, $\gamma$-GTP gamma-glutamyl transpeptidase, BUN blood urea nitrogen, Cre creatinine, Vit vitamin 

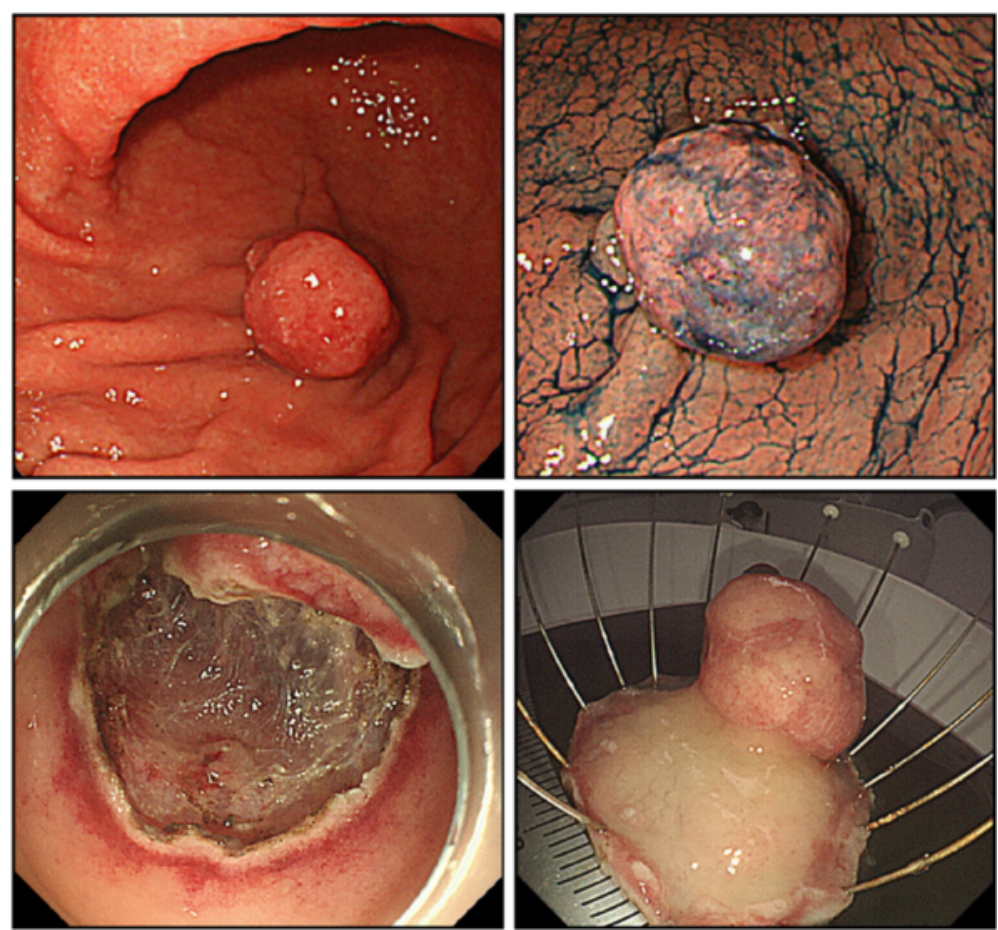

Fig. 3 Endoscopic submucosal dissection. En bloc endoscopic submucosal dissection was performed for the pedunculated polyp, measuring $20 \mathrm{~mm}$ in diameter, on the greater curvature of the lower gastric body

Consequently, additional radical distal gastrectomy was performed. Examination of the surgical specimens showed a scar resulting from the endoscopic submucosal dissection on the anterior wall of the gastric body. There were no residual tumor cells or lymph node metastasis. Examination of the background mucosa showed that the proper gastric glands in the pyloric region were preserved, while those in the mucosa of the gastric body were atrophic and showed intestinal metaplasia and pseudo-pyloric metaplasia (Fig. 5). In the OLGA staging system, the corpus and the antrum were scored as 2 and 0 , respectively, indicating stageII gastritis at the time of surgery $[10,11]$. Chromogranin A staining revealed enterochromaffin-like cell hyperplasia (linear hyperplasia and micronodular hyperplasia) (Fig. 5b, arrows indicate micronodular hyperplasia). H. pylori infection was negative (Fig. 5).

\section{Conclusions}

The classification of chronic gastritis into types A and B was proposed by Strickland et al. [12]. However, currently, there are no established diagnostic criteria for the diagnosis of type A gastritis. Traditionally, type A gastritis has been diagnosed based on the anti-gastric parietal and anti-intrinsic factor antibody findings, presence of corpus-predominant atrophic gastritis, and serum gastrin levels, with Ban et al. stating that asymptomatic type A gastritis could be diagnosed by anti-gastric parietal antibody [13]. The prevalence of autoimmune gastritis is unclear $[13,14]$. In the early stage, the diagnosis of type A gastritis is difficult even with a biopsy, since the symptoms of anemia due to malabsorption of vitamin B12 and iron usually develop at a later stage. In the present case, we considered that the patient was not infected with $H$. pylori, because her serum $H$. pylori immunoglobulin $\mathrm{G}$ antibody, stool $H$. pylori antigen, and histological examination were all negative. On the other hand, the patient was positive for anti-gastric parietal cell and anti-intrinsic factor antibodies, and had a markedly elevated level of serum gastrin and reduced pepsinogenI level and pepsinogenI/II ratio. Moreover, the patient had corpus-predominant atrophic gastritis, OLGA stageII, and enterochromaffin-like cell hyperplasia. Taken together, these findings led to the diagnosis of type A chronic atrophic gastritis. Although we did not have the sufficient histological data from the first endoscopy performed in 2005, mild corpus atrophy was detected at that time. Rugge et al. reported that in 116 patients with autoimmune gastritis, 87 cases (75.0\%) remained and 25 cases (21.6\%) progressed to a higher OLGA gastritis stage during a mean follow-up period of 54 months (range, 24-108 months) [11]. Considering the gastritis stage in 2014, the present case can thus be speculated to have been at stageI orII in 2005. Type A gastritis is characterized by the presence of hypergastrinemia associated with reduced gastric acid secretion. Gastrin is a peptide hormone synthesized and released mainly from $G$ 


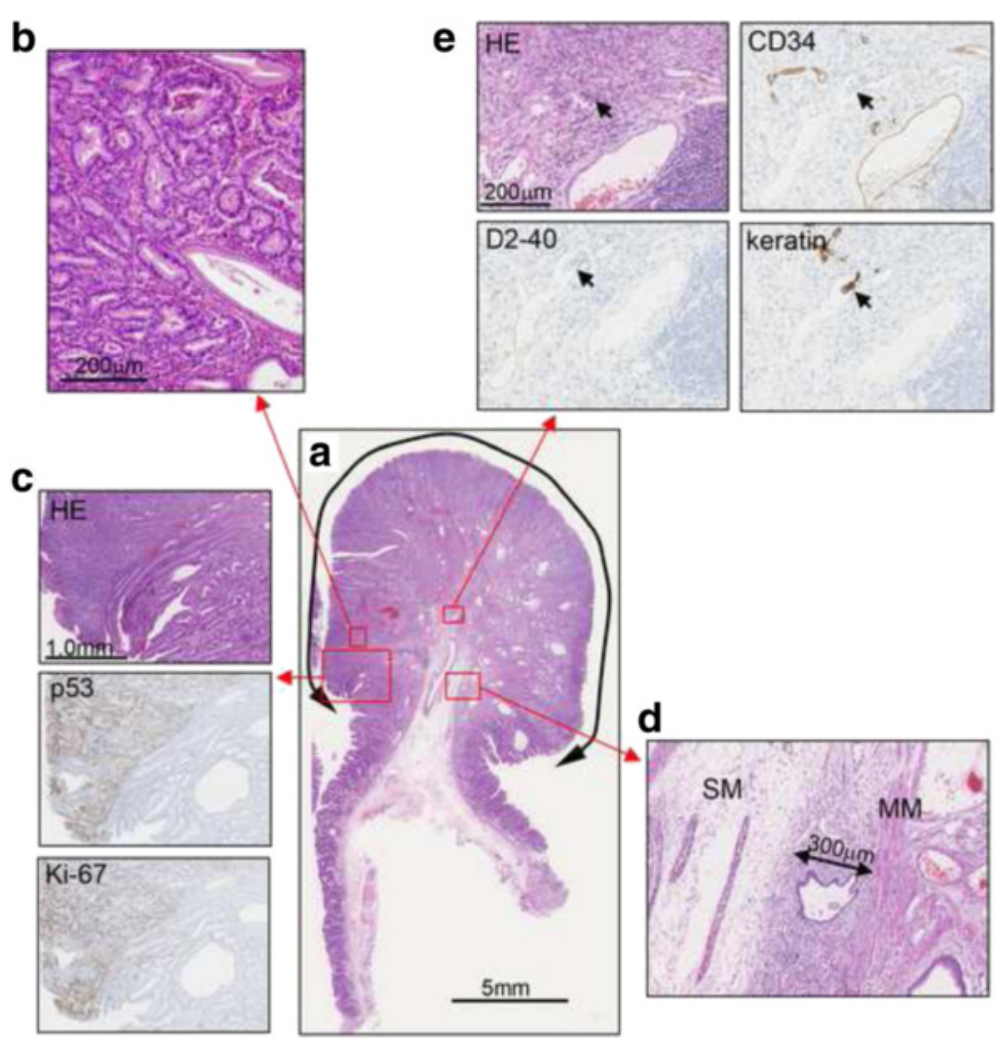

Fig. 4 Histological findings. a. Hematoxylin and eosin (HE) staining. b. High magnification image of the boxed area. c. HE, p53, and Ki-67 stainings of the border between the hyperplastic glands and the tumor glands. The tumor lesions were strongly positive for p53 and Ki-67. d. Submucosal invasion in the stalk, with an invasion depth of $300 \mu \mathrm{m}$ (MM, muscularis mucosae; SM, submucosal layer). e. HE, cluster of differentiation 34 (CD34), D2-40, and keratin staining. In CD34-negative and D2-40-positive lymph ducts, keratin-positive cells with acidophilic cytoplasm and large nuclei were observed, indicating lymphatic invasion (arrows)

cells in the gastric antrum, which plays a role in the regulation of gastric acid secretion and gastrointestinal motility [15]. Furthermore, it is known to exert trophic actions on digestive cells $[16,17]$. In the present patient, it was suggested that the GFHP had grown during the nine-year follow-up period, owing to her hypergastrinemia; her serum gastrin level was $>3000 \mathrm{pg} / \mathrm{ml}$ before undergoing distal gastrectomy, but decreased to $74 \mathrm{pg} / \mathrm{ml} 48 \mathrm{~h}$ after the surgery.

The process of cancer development is considered to be a multistage process (hyperplasia $\rightarrow$ dysplasia $\rightarrow$ carcinoma); that is, as the polyp grows and becomes more dysplastic, the risk of cancer increases [2, 5, 18, 19]. The most important risk factors of malignant transformation in chronic atrophic gastritis include age over 50 years, severe atrophy, and the presence of intestinal metaplasia extension [20]. The present patient fit the first and third risk factors. Rugge et al. reported that the risk of cancer was restricted to case of high-risk gastritis stage (OLGA stages III-IV) and that it was associated mainly with concomitant $H$. pylori infection [11]. However, malignant transformation in type A gastritis associated with hypergastrinemia might be induced at an earlier gastritis stage. Several genetic alterations have been revealed in hyperplastic polyps, including abnormal expression of tumor suppressor p53, K-ras mutations, and microsatellite instability $[18,21]$. Shibahara et al. conducted a study of gastric hyperplastic polyps and reported that increased expression of p53 was observed in dysplastic and carcinoma cells but not in the normal or hyperplastic cells, and that the expression of Ki67 was higher in the carcinoma and dysplastic cells than in the hyperplastic cells. They suggested that examinations of p53 and Ki67 were useful markers of malignant transformation of gastric hyperplastic polyps [22]. Yao et al. and Zea-Iriarte et al. also suggested that p53 plays an important role in the malignant transformation of gastric hyperplastic polyps [19, 23]. In the present case, the expression of p53 was strongly positive in the carcinoma cells and Ki67 was positive in approximately $50 \%$ of the carcinoma cells, while these stainings were much decreased in the non-transformed cells (Fig. 4b).

The reported incidence of malignant transformation of GFHP ranges from 0.6 to $4.5 \%$ [1-5], and Fujino et al. reported that the mean diameter of GFHPs with malignant transformation was as large as $23.4 \pm 10.2 \mathrm{~mm}$ [24]. 


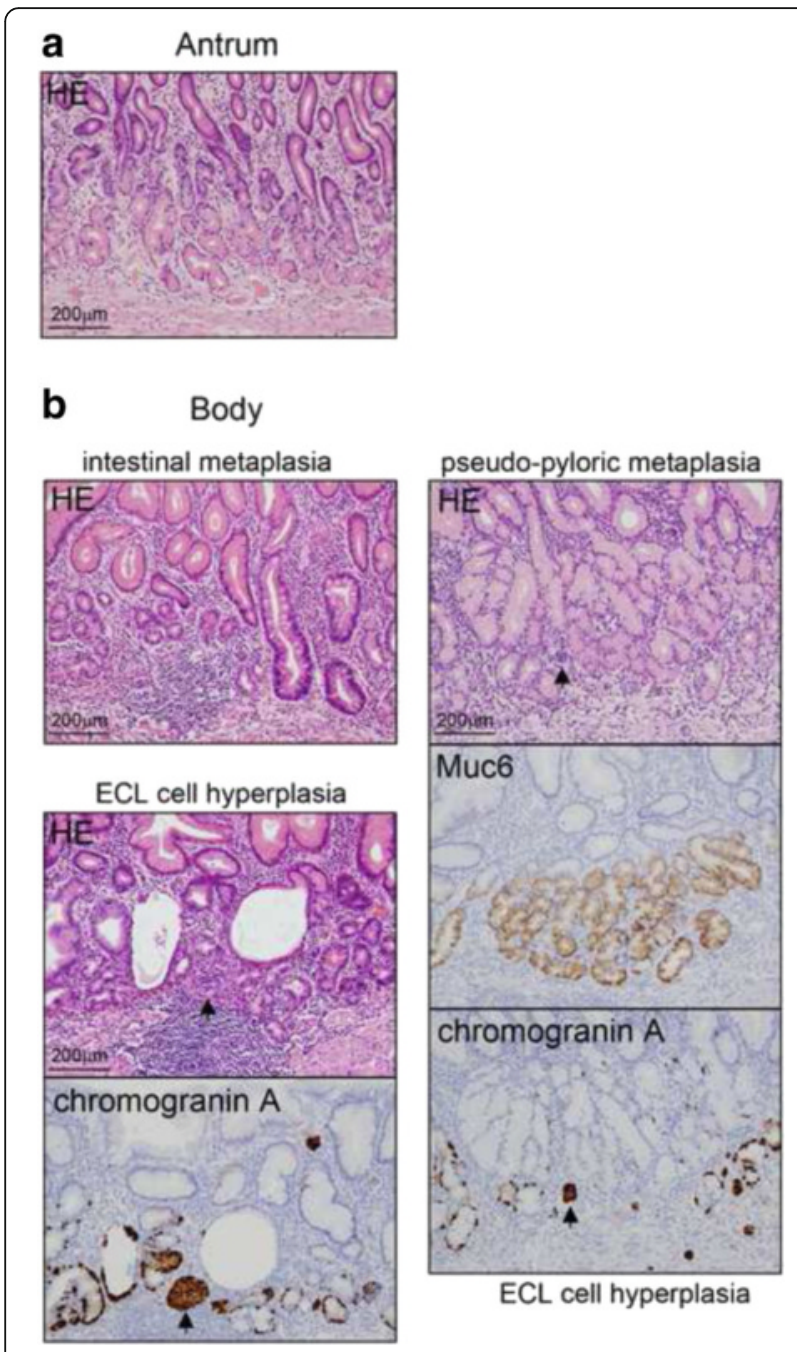

Fig. 5 Examination of the background mucosa. a. The proper gastric glands in the pyloric region were preserved. There was no atrophic change. $\mathbf{b}$. The proper gastric glands in the gastric body. The mucosa was atrophic and showed intestinal metaplasia and pseudo-pyloric metaplasia. Muc6 is a gastric pyloric gland- type secretory mucin. Enterochromaffin-like cell hyperplasia (linear hyperplasia and micronodular hyperplasia (arrows)) was revealed by chromogranin A staining

Regarding the histological type, most previously reported cases were differentiated adenocarcinomas, while a few were poorly-differentiated adenocarcinomas or signet ring cell carcinomas [25-28]. The GFHP in the present patient was $20 \mathrm{~mm}$ in diameter and histologically diagnosed as differentiated adenocarcinoma (Fig. 4).

The diagnostic criteria of malignant GFHP proposed by Nakamura et al. in 1985 are as follows [29]: 1) coexistence of benign and malignant parts in the same polyp; 2) existence of sufficient evidence that the benign area has previously been a benign polyp; and 3) existence of sufficient cellular and structural atypia in the malignant area to be diagnosed as cancer. The patient in the present study met these criteria and was therefore diagnosed with malignant transformation of GFHP over nine years. GFHPs with carcinoma have been reported to have the following macroscopic characteristics: pedunculated form, larger size (>20 mm), reddish color, irregular or nodular surface, white-coated, and bleeding tendency [2, 23, 25, 30, 31]. Our patient displayed four of these macroscopic features, including pedunculated form, a diameter $>20 \mathrm{~mm}$, growth tendency, and a white-coated lesion.

It has been reported that magnifying endoscopy with narrow band imaging is useful for the diagnosis of cancer [32-34]; however, it is not sufficiently useful for diagnosing malignant transformation of gastric hyperplastic polyps [23]. Ahn et al. reported that GFHPs measuring $10 \mathrm{~mm}$ or larger in diameter should be endoscopically resected [35], whereas Tanabe et al. reported the disappearance of a $20 \mathrm{~mm}$ hyperplastic polyp with malignant transformation after $H$. pylori eradication therapy [36]. The lesion in the present patient was diagnosed as tubular adenocarcinoma on biopsy. Endoscopic estimation of the invasion depth of the carcinoma was difficult; hence, endoscopic submucosal dissection, a minimally invasive procedure, was performed. The results showed a submucosal invasion depth of $0.3 \mathrm{~mm}$ and lymph duct invasion. Subsequently, we performed additional distal gastrectomy and lymph node dissection. There was no distant metastasis, and we considered that complete removal of the tumor was achieved. At the time of this report, the patient has been followed-up for 12 months after surgery with no recurrence.

To our knowledge, there are only a few previous cases, limited to Japan, of malignant GFHP with submucosal invasion requiring surgical treatment $[37,38]$, and there are no previous reports on malignant transformation of GFHP with submucosal invasion and lymphatic invasion arising in a background of type A gastritis in the English literature. Thus, the present case is considered very rare and to provide valuable information. Importantly, there is currently no effective treatment other than endoscopic or surgical treatment for GFHPs, secondary to type A gastritis. Moreover, as this type of polyp has a potential risk of malignant transformation due to hypergastrinemia, endoscopic or surgical treatment should be considered when malignant transformation is suspected.

\section{Abbreviation}

GFHP: Gastric foveolar hyperplastic polyp

\section{Acknowledgements}

None.

\section{Funding}

None.

Availability of data and materials Not applicable. 


\section{Authors' contributions}

YK, MH, YY, IT, TO, NM, and MH performed the research; YK designed the research, analyzed the data, and wrote the paper; AS revised the manuscript critically. All authors read and approved the final manuscript.

\section{Competing interests}

The authors declare that they have no competing interests.

\section{Consent for publication}

Written consent was obtained from the patient.

\section{Ethics approval and consent to participate}

Written consent was obtained from the patient. As this is a case report, approval from the Etiological Study Ethical Review Board of Saitama Medical Center, Jichi Medical University was not needed.

\section{Author details}

'Department of Gastroenterology, Jichi Medical University, Saitama Medical Center, Saitama 330-8503, Japan. ²Department of Surgery, Jichi Medical University, Saitama Medical Center, Saitama 330-8503, Japan. ${ }^{3}$ Department of Pathology, Jichi Medical University, Saitama Medical Center, Saitama 330-8503, Japan

Received: 6 April 2016 Accepted: 29 September 2016

\section{Published online: 12 October 2016}

\section{References}

1. Abraham SC, Singh VK, Yardley JH, Wu TT. Hyperplastic polyps of the stomach: associations with histologic patterns of gastritis and gastric atrophy. Am J Surg Pathol. 2001;25:500-7.

2. Daibo $M$, Itabashi $M$, Hirota T. Malignant transformation of gastric hyperplastic polyps. Am J Gastroenterol. 1987;82:1016-25

3. Orlowska J, Jarosz D, Pachlewski J, Butruk E. Malignant transformation of benign epithelial gastric polyps. Am J Gastroenterol. 1995;90:2152-9.

4. Hattori T. Morphological range of hyperplastic polyps and carcinomas arising in hyperplastic polyps of the stomach. J Clin Pathol. 1985;38:622-30.

5. Terada T. Malignant transformation of foveolar hyperplastic polyp of the stomach: a histopathological study. Med Oncol. 2011;28:941-4.

6. Coati I, Fassan M, Farinati F, Graham DY, Genta RM, Rugge M. Autoimmune gastritis: pathologist's viewpoint. World J Gastroenterol. 2015;21:12179-89.

7. Ljubicić N, Banić M, Kujundzić M, Antić Z, Vrkljan M, Kovacević I, et al. The effect of eradicating Helicobacter pylori infection on the course of adenomatous and hyperplastic gastric polyps. Eur J Gastroenterol Hepatol. 1999;11:727-30

8. Bonilla Palacios JJ, Miyazaki Y, Kanayuma S, Yasunaga Y, Matsuzawa Y. Serum gastrin, pepsinogens, parietal cell and Helicobacter pylori antibodies in patients with gastric polyps. Acta Gastroenterol Latinoam. 1994;24:77-82.

9. Okusa T, Takashimizu I, Fujiki K, Suzuki S, Shimoi K, Horiuchi T, et al. Disappearance of hyperplastic polyps in the stomach after eradication of Helicobacter pylori. A randomised, clinical trial. Ann Intern Med. 1998;129:712-5.

10. Rugge M, Correa P, Di Mario F, El-Omar E, Fiocca R, Geoboes K, et al. OLGA staging for gastritis: a tutorial. Dig Liver Dis. 2008:40:650-8.

11. Rugge M, Fassan M, Pizzi M, Zorzetto V, Maddalo G, Realdon S, et al Autoimmune gastritis: histology phenotype and OLGA staging. Aliment Pharmacol Ther. 2012;35:1460-6.

12. Strickland RG, Mackay IR. A reappraisal of nature and significance of chronic atrophic gastritis. Am J Dig Dis. 1973;18:426-40.

13. Toh $\mathrm{BH}$. Diagnosis and classification of autoimmune gastritis. Autoimmun Rev. 2014;13:459-62.

14. Toh BH, Chan J, Kyaw T, Alderuccio F. Cutting edge issues in autoimmune gastritis. Clin Rev Allergy Immunol. 2012;42:269-78.

15. Dockray GJ, Varro A, Dimaline R, Wang T. The gastrins: their production and biological activities. Annu Rev Physiol. 2001;63:119-39.

16. Smith AM, Watson SA. Review article: gastrin and colorectal cancer. Aliment Pharmacol Ther. 2000;14:1231-47.

17. Rozengurt E, Walsh JH. Gastrin, CCK, signaling, and cancer. Annu Rev Physiol. 2001:63:49-76

18. Dijkhuizen SM, Entius MM, Clement MJ, Polak MM, Van den Berg FM, Craanen $\mathrm{ME}$, et al. Multiple hyperplastic polyps in the stomach: evidence for clonality and neoplastic potential. Gastroenterology. 1997;112:561-6.
19. Yao T, Kajiwara M, Kuroiwa S, Iwashita A, Oya M, Kabashima A, et al. Malignant transformation of gastric hyperplastic polyps: alteration of phenotypes, proliferative activity, and p53 expression. Hum Pathol. 2002;33:1016-22.

20. Vannella L, Lahner E, Annibale B. Risk of gastric neoplasias in patients with chronic atrophic gastritis: a critical reappraisal. World J Gastroenterol. 2012;18:1279-85.

21. Nogueria AM, Carneiro F, Seruca R, Cirnes L, Veiga I, Machado JC, et al. Microsatellite instability in hyperplastic and adenomatous polyps of the stomach. Cancer. 1999:86:1649-56.

22. Shibahara K, Haraguchi Y, Sasaki I, Kiyonari H, Oishi T, Iwashita A, et al. A case of gastric hyperplastic polyp with malignant transformation. Hepatogastroenterology. 2005;52:319-21.

23. Zea-Iriarte WL, Sekine I, Itsuno M, Makiyama K, Naito S, Nakayama T, et al. Carcinoma in gastric hyperplastic polyps. A phenotypic study. Dig Dis Sci. 1996;41:377-86.

24. Fujino M, Yamamoto Y, Morozumi A, Kawai T. Malignant transformation of gastric polyps. Nihon Rinsho. 1991;49:155-9 [article in Japanese].

25. Zea-Iriarte WL, Itsuno M, Makiyama K, Hara K, Haraguchi M, Ajioka Y. Signet ring cell carcinoma in hyperplastic polyp. Scand J Gastroenterol. 1995;30:604-8.

26. Fry LC, Lazenby AL, Lee $\mathrm{DH}$, Mönkemüller K. Signet-ring-cell adenocarcinoma arising from a hyperplastic polyp. Gastrointest Endosc 2005:61:493-5.

27. Gotoh Y, Fujimoto K, Sakata Y, Fujisaki J, Nakano S. Poorly differentiated adenocarcinoma in a gastric hyperplastic polyp. South Med J. 1996:89:453-4.

28. Hirasaki S, Suzuki S, Kanzaki H, Fujita K, Matsumura S, Matsumoto E. Minute signet ring cell carcinoma occurring in gastric hyperplastic polyp. World J Gastroenterol. 2007;13:5779-80

29. Nakamura T, Nakano G. Histological classification and malignant change in gastric polyps. J Clin Pathol. 1985;38:754-64.

30. Mitsufuji S, Tsuchihashi Y, Isetani K, Tokita K, Maruyama K, Hosokawa Y, et al. A ten-year observation of malignant changes in a hyperplastic polyp of the stomach-a cellular kinetic study using bromodeoxyuridine (BrdU). Gan No Rinsho. 1990:36:1035-41 [article in Japanese].

31. Yamaguchi K, Shiraishi G, Maeda S, Kitamura K. Adenocarcinoma in hyperplastic polyp of the stomach. Am J Gastroenterol. 1990:85:327-8.

32. Hirano H, Yoshida T, Yoshimura H, Fukuoka M, Ohkubo E, Tachibana S, et al. Poorly differentiated adenocarcinoma with signet-ring cell carcinoma in a hyperplastic polyp of the stomach: report of a case. Surg Today. 2007:37:901-4.

33. Yao K, Oishi T, Matsui T, Yao T, Iwashita A. Novel magnified endoscopic findings of microvascular architecture in intramucosal gastric cancer. Gastrointest Endosc. 2002;56:279-84.

34. Yao K, Takaki Y, Matsui T, Iwashita A, Anagnostopoulos GK, Kaye P, et al. Clinical application of magnification endoscopy and narrow-band imaging in the upper gastrointestinal tract: new imaging techniques for detecting and characterizing gastrointestinal neoplasia. Gastrointest Endosc Clin N Am. 2008;18:415-33.

35. Ahn JY, da Son H, Choi KD, Roh J, Lim H, Choi KS, et al. Neoplasms arising in large gastric hyperplastic polyps: endoscopic and pathologic features. Gastrointest Endosc. 2014:80:1005-13.

36. Tanabe H, Hara H, Ohkubo C, Miyokawa N, Sano H. Disappearance of gastric adenocarcinoma in hyperplastic polyp after eradication of Helicobacter pylori. Nihon Shokakibyo Gakkai Zasshi. 2005;102:559-63 [article in Japanese].

37. Nimura $H$, Kashiwagi $H$, Mitsumori $N$, Arai $Y$, Yonezawa J, Kaise M, et al. The easy endoscopic polypectomy of gastric hyperplastic polyp should not be carried out. Shokaki Geka. 2007;30:569-79 [article in Japanese].

38. Yamashita S, Kaise M. Malignant transformation in a case of gastric hyperplastic polyp. Shokaki Naishikyo. 2015;27:101-5 [article in Japanese]. 